\title{
Developing 3D models of pre-war Warsaw buildings using spatial data integration
}

\author{
Justyna Bak, Beata Calka \\ ${ }^{a}$ Military University of Technology, Institute of Geospatial Engineering and Geodesy, email: justyna.bak@student.wat.edu.pl, \\ beata.calka@wat.edu.pl \\ * Corresponding author: Beata Calka beata.calka@ wat.edu.pl
}

Keywords: 3D modelling, cartographic heritage, data integration

Abstract:

Warsaw is a city repeatedly damaged during World War II. The first destruction occurred during its bombing in September 1939. After the fall of the Warsaw Ghetto Uprising in May 1943, the entire district was razed to the ground. During the Warsaw Uprising in August and September 1944, the city was destroyed by artillery shelling, bombardments, and fires. After the surrender and evacuation of civilians in October 1944, even more buildings were blown up. Almost $90 \%$ of Warsaw was destroyed, with burnt-out tenement houses, collapsed ceilings and walls, and torn-down valuable monuments of up to 300 years. After the war, it was not possible to rebuild many of them. Nevertheless, valuable historical materials remain, documenting the past of valuable Warsaw buildings.

The aim of the research was to develop a methodology for integrating cartographic materials and other spatial data to create 3D models of the interwar buildings in Warsaw. The materials for the studies were obtained from the National Archives in Warsaw. They consisted of historical maps, ground and aerial photographs, as well as construction drawings and architectural designs of the buildings. Depending on the availability of historical sources, three different approaches of 3D model developing were proposed. An example of a building for which a 3D model was developed is Grand Synagogue (blown up in 1943), building of Kamienica Theater (the building is largely burned down) and Buildings of Tłomackie (destroyed in 1944). An important stage in 3D model development was the processing and calibration of historical photographs and tacheometric surveying to measure the buildings in the vicinity of the tenement house on Tłomackie square.

The proposed methodology shows that it is possible to recreate 3D images of historical buildings, even those no longer existing, using old cartographic materials and spatial data from various sources. Cartographic heritage supported by digital technologies in combination with other documents of cultural heritage can help reveal fragments of the city's stories and depict them in a interesting way. The described method can enrich the perception of Warsaw's past by its residents, as well as by professionals, such as historians, archivists, or cartographers. 